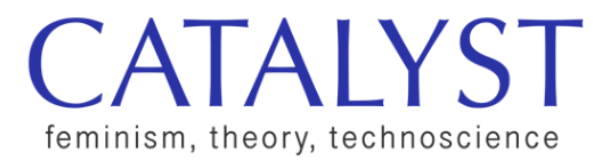

\title{
Book Review | Going Stealth: Transgender Politics and U.S. Surveillance Practices, by Toby Beauchamp (Duke University Press, 2019)
}

Tony Wei Ling

UCLA

tonyweiling@g.ucla.edu

What does it mean to become visible? Toby Beauchamp's 2019 monograph Going Stealth does not ask this question of trans people, exactly, or even of any particular group; the "subjectless critique" that it undertakes declines a central figure for its inquiries. The question is not, "what does visibility mean for trans people?"--a tired, or tiring, question nevertheless echoed out in intra-community fights. Instead, the question of this book assesses the mechanics and technologies of visibility itself: What does visibility promise to the state, and what does the promise of visibility attempt to secure, vanish, or replace?

In developing a subjectless trans critique, Beauchamp's gesture is not a vacantly anti-identitarian one, as I somewhat worried over when beginning its Introduction. Unsurprisingly indebted to Foucault, Going Stealth's study of gender-haunted surveillance measures and securitization gives a history of the tools by which compliance and noncompliance are manufactured-the X-ray, the backscatter machine, the identification card, the trial of Chelsea Manning (p. 14). This strategy means that we can frame the question of visibility not by what "being seen" offers as an idealistic aim or cynical strategy or even an inescapable trap, but by what searching and being searched has to do with compliant citizenship. Rather than examining the ways that trans people get caught in the jaws of surveillance, Beauchamp aims to show how gender nonconformity and

Wei Ling, Tony (2020). Review of Going Stealth: Transgender Politics and U.S. Surveillance Practices (Duke University Press, 2019). Catalyst: Feminism, Theory, Technoscience, 6(2), pp. 1-5.

http://www.catalystjournal.org| ISSN: 2380-3312

(c) Tony Wei Ling, 2020 | Licensed to the Catalyst Project under a Creative Commons Attribution Non-Commercial No Derivatives license 
trans-identified subjects are an essentially productive problem for surveillance practices. The continued misapprehension of gender nonconformity as "inherently deceptive," Beauchamp writes, creates the justification for "continued surveillance to locate its truth" (p. 134). For this project, then, what drives and intensifies surveillance is not simply a hatred and distrust of trans people as a group, but a broader (if certainly transphobic) anxiety about the impossibility of securing gender for identification purposes. To the extent that gender is mutable, variable, or non-visual, it cannot serve its purpose as a stable identifying marker; the anxiety generated from that instability is in turn the legitimizing force for each new measure aiming to separate the safe from the unsafe person, the healthy from the threatening body.

Importantly, Beauchamp emphasizes, the groups affected and targeted by these measures are not only (even primarily) those who would describe themselves as trans. Ableism, bourgeois phobias about sexual behavior, and racism of multiple stripes-anti-Muslim, anti-Black, anti-immigrant--all drive the fearful violence that surveillance visits upon the "gender non-conforming" figure. Beauchamp's critique builds upon the work of Jasbir Puar, Amit Rai (2002), and Cathy Cohen (1997), all of whom have written about the way that marginalized people can be marked by queerness or (more broadly) sexual deviance without being themselves "queer." By carefully refusing the version of this project that would train its eye on trans people, Beauchamp opens up an analysis that scrutinizes gender regulation's involvement in border control, war crimes, and anti-terrorist surveillance.

Chapters 1 and 2 of Going Stealth outline the respective histories of the standardized identification document and the airport scanner. In the former, Beauchamp emphasizes the standardization of documents as a process of codification, by which documents understood to simply describe qualities like race or gender actually generate and attempt to secure them as factual reports. The chapter begins with standardized manumission papers, then traces the regulation of photo IDs around the moment of Chinese Exclusion. These histories are present in contemporary fights around securitizing immigration, anti-terrorism, and voting, which so often frame falsified documents as proof of "a fundamentally deceptive personality...shared across certain marginalized groups" (p. 27). A racist anxiety about truth, ID, and citizenship is always already intertwined with a heterosexist anxiety about those same things, where fears of gender mutability may be used to "play on racial anxieties about voter fraud without explicitly referencing race," shoring up the lines of legitimate belonging (p. 30). 
In the second chapter's history of air travel, X-rays, and backscatter machines, the problem of strategic disclosure that ends Chapter 1 is developed further alongside the recourse that transgender advocates have made to claiming "medical necessity" for prosthetic and non-prosthetic bodily anomalies on trans bodies. Travel recommendations that suggest trans travelers disclose their status, and transgender advocates arguing for gender-related prosthetics as medical necessities attempt to bargain for a more progressive and sensitive Transportation Security Administration (TSA), but cannot resolve the problem of how to differentiate legitimate, docile transgender flyers from threatening ones only interpreted as gender-nonconforming. "How will bodily anomalies be redefined, as bodily normality is incrementally expanded through these alterations?" Beauchamp asks (p. 76).

Chapter 3, which focuses on bathrooms bills and the odd intimacy between public bathrooms and "good citizenship," tracks a fascinatingly informal kind of surveillance based in an imagined community of middle-class bathroom-users, whose privacy and security is apparently at risk. Yet the very incoherence of the proposed laws that might lock down those bathrooms by a "common-sense" approach to bodily assessment or by an ill-conceived "complaint basis" nonetheless work overtime to render intense scrutiny a public norm, and intensifies the adjudication of both gendered and national/racial belonging in public spaces (p. 104). This logic of bodily assessment, Beauchamp argues, is inherently tied to biometric surveillance programs, which attempts to gather, sort, and interpret apparently unchangeable physical markers to secure places like government buildings and airports (p. 95). Most importantly, perhaps, the focus on the individual body as a form of proof deflects "critical assessment of the spaces in which those bodies are situated," putting the onus of suspicion on the body rather than the public place it dares to inhabit (p. 101).

In Going Stealth's final chapter, on Chelsea Manning's trial, Beauchamp takes on his most difficult case study. The trial's discursive attempts to make Manning's own gender secrets or "deception" the subject of scrutiny is Beauchamp's point and true subject, but because of the continuing exposure and importance of Manning as an incarcerated whistleblower, delivering an analysis of Manning's trial but not Manning proves incredibly delicate and difficult work. This chapter clarifies, however, one of the book's most urgent questions: How do narrative frames, analogies, and analytical habits inevitably submerge one thing in order to 
secure or make visible another? It is easy, this book acknowledges, to misemphasize and make visible a single subject or group affected by a violent structure, elevating one subject to "visibility" by necessarily submerging others. In this last chapter, Beauchamp demonstrates the rhetorical bait-and-switch of Manning's "secrets" with state secrets, where the hypervisibility of the former became an opportunity to secure the latter.

One important effect of Beauchamp's focus on the compulsory mechanisms of public life (such as ID documents, X-rays, and public bathrooms) is the displacement of an often-lionized posture of noncompliance. Within Going Stealth, individual deviation or refusal is not held to be a heroic resistance to capture by the state; rather, "noncompliance" becomes the central term describing an attributed, involuntary quality of threatening difference. What does it mean, Beauchamp wonders instead, to be unable to be compliant? His final chapter cites the 2008 police assault on Duanna Johnson, a Black trans woman arrested, harassed, and beaten by booking officer Bridges McRae, in which a preponderance of surveillance footage from body cameras and county jails was used as evidence not only by Johnson's counsel, but by the violent cop who filed his own assault charge against Johnson (p. 111). For this case as well as others, noncompliance is not a prescription for resistance, certainly not at an individual level, but a constant and ordinary fact of perception. The problem with visibility, then, is being seen, for there is no real gap between the state and civil society: surveillance works through informal as well as formal means, "through capillary networks of power not confined to areas commonly associated with the state itself" (p. 17).

Becoming illegible and so ungovernable has its appeal. But as the Epilogue, "On Endurance," concludes, "surveillance practices thrive on the illegibility that they themselves assign to certain populations," and gender nonconformity alone--like queerness itself-can hardly deliver "an inherently resistant foil to the workings of surveillance" (p. 140). Individual and group noncompliance alike become excuses for further force, more intense scrutiny, and new forms of surveillance. Like many monographs, Going Stealth gives just a wisp of an idea of what would serve as a possible strategy, even as it attempts to leave the reader in the arena of political response. This half-step ends the book on a note of prevarication, particularly unsatisfying given the urgency of its diagnostic, and potentially suggesting that state technologies and strategies are too totalizing and dynamic to ever overthrow. Still, I admire this book's commitment to the descriptive before the aspirational, and its emphatic argument that we cannot romanticize illegibility or 
evasion as an enduring politic. Beauchamp's Going Stealth is a careful meshwork of historical and political analysis, attentive to the problems of existing critical frames.

\section{References}

Cohen, C. (1997). Punks, bulldaggers, and welfare queens: The radical potential of queer politics?" GLQ, 3(4): 437-65.

Puar, J., \& Amit, R. (2002). Monster, terrorist, fag: The war on terrorism and the production of docile patriots." Social Text, 20(3): 117-48.

\section{Author Bio}

Tony Wei Ling is a comics critic, graduate student, and fiction editor. They are a managing editor at Nat.Brut, and they study contemporary fiction, comics, and new media at UCLA. 